\title{
The role of sleep in Juvenile idiopathic arthritis patients and their caregivers
}

\author{
Karen Tieme Nozoe, Daniel Ninello Polesel, André Campiolo Boin, Laís Fernanda Berro, Gustavo Antônio Moreira, \\ Sergio Tufik and Monica Levy Andersen*
}

\begin{abstract}
Juvenile idiopathic arthritis is a chronic disease that may lead to various consequences for patients and caregivers, especially in relation to sleep quality. Sleep is an essential process for homeostasis of the organism. In general, caregivers of children with JIA are more susceptible to these sleep disorders and a lower quality of life. This impairment in sleep can potentially affect the health of caregiver. For this reason, it is very important to continue to evaluate the quality of sleep in caregivers and how to support these JIA children's caregivers more effectively.
\end{abstract}

Keywords: Juvenile idiopathic arthritis, Sleep, Caregivers

\section{Commentary}

Recently an important article was published in the Pediatric Rheumatology by Mawani and colleagues, describing the impact of caregiving on parents of children with Juvenile Idiopathic Arthritis (JIA) [1]. We would like to congratulate the authors for their interesting study. The aim of this commentary is to discuss JIA children and their caregivers, particularly regarding the impact of this parental assistance on these parents' health.

JIA is the most common chronic arthritis disease in children. In the US, 300,000 children younger than 16 years are affected by JIA [2]. This disease may lead to multiple impairments, such as joint deformity, growth impairment and chronic pain. The pain is generally the most distressing of the symptoms. In addition, pain can negatively impact the quality of life of each child leading to physical, social and emotional disabilities. The pathogenesis of pain is multifactorial, and includes genetic, anatomical [3] and psychological influences as well as the contribution of environmental factors [4]. Patients with chronic pain often suffer from sleep disturbances, which affect sleep quality and may increase clinical complaints. Sleep disorders and daytime sleepiness are a result of physiological imbalances that can lead to health problems, such as diminished social, physical and cognitive performances [5].

\footnotetext{
* Correspondence: ml.andersen12@gmail.com

Department of Psychobiology, Universidade Federal de São Paulo, São Paulo,
} SP, Brazil

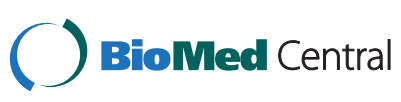

It is noteworthy that children with JIA may present with poor sleep quality, daytime sleepiness [6], sleep anxiety, night awakenings, parasomnias and sleep disordered breathing [7]. Moreover, patients with JIA have increased risk for sleep apnea, because of changes in facioskeletal features, mainly due to a high chance for posterior rotation of mandible and retrognathia [8]. Sleep is an essential physiologic process for the body homeostasis, especially for the physical development of children and for their immune system. Sleep in childhood corresponds to $40 \%$ of the child's daytime [9], thereby demonstrating the importance of sleep in this stage of life.

This chronic disease and neuro-inflammatory symptoms in children may lead several consequences to their health [10]. There is a bidirectional relationship between pain and disrupted sleep [6], especially regarding sleep impairment, which can exacerbate pain symptoms [11]. However, results from several studies are not conclusive about the mechanism of action of pain in sleep disorder conditions. One possible explanation is that sleep deprivation produces hyperalgesic changes by inducing a decrease of mu- and delta-opioid receptors in the limbic system [12] and reduced affinity of delta- and mu-opioid receptors [13]. Furthermore, sleep deprivation can affect the pharmacological treatment of pain through by inhibiting the analgesic action of painkillers [12,13].

In addition to the sleep-pain cycle, sleep disturbances may lead to other negative health consequences such as impairment and dysregulation of the immune system. 
Regarding JIA, the patient's stressful life might be the trigger of an increased inflammatory response [14] that can contribute itself to sleep impairment and the poor sleep may in turn cause an increase in proinflammatory cytokines levels [15]. Thus, sleep deprivation weakens the immune system, changing the activity of immune cells. An important preclinical study showed that sleep deprivation in mice resulted in earlier onset of immune disorders [16], suggesting that sleep impairment could be a risk factor for the onset of any of these disease. We would like to also suggest that a child with undiagnosed chronic pain syndrome that is associated with sleep deprivation should have an appointment with a sleep physician for a sleep evaluation. Thus we must emphasize the importance of sleep for JIA patients. Inside the family circle, the mother often has a fundamental role in the sleep habits of the child.

According with the International Classification of Sleep Disorders, children may have a delayed sleep when their daytime lifestyle is inappropriate or stressful [17]. The mother's sleep habits may have a strong influence on their children's sleep as well [18]. In turn, JIA may affect the health of primary caregivers as well, mainly by stress and psychological symptoms [19]. The consequences on the quality of life of primary caregivers still are unclear, but there are some trends such as social, emotional and financial impact in families [20].

Sleep is also affected in caregivers, what can have negative effects on their physical and psychological health [21]. Hence, sleep in caregivers is a relevant aspect that should be considered, especially regarding caregivers of patients suffering from chronic diseases such as JIA. Caregivers often have reduction of total sleep time, increased arousals, insomnia and sleep deprivation [22]. These conditions can potentially affect the health of the caregiver and cause immune [23] and cardiovascular [24] effects, as well as psychological distress [25]. We would like to emphasize that the sleep patterns can vary due to individual situations; parents that take care of children suffering from diseases with a high frequency of requests or need for care by the caregiver may suffer more. Often caregivers are susceptible to burden, burnout syndrome, depression, and a lower quality of life [26] is crucial or the ability to be able to care for the patient or family member will come only with great effort.

The mother-care giver can assist in the sleep hygiene practice and in the development of the physical and psychological health of your child. As the treatment of children with JIA involves a multidisciplinary approach, it should include an evaluation of the sleep quality of the patient and parents, both for the well-being of the patient and their caregivers. Regarding the child, this evaluation should be performed with the integration between clinical history, physical examination and laboratory analysis.
Also, the evaluation of the habits and routines of patients over a 24 hour day and night cycle is necessary, focusing on a detailed description of sleep habits on weekdays and weekends (bedtime routine, night time behaviors and naps). Children with JIA suffer from frequent insomnia that may require treatment through cognitive behavioral therapy (CBT). This CBT is recommended by the American Academy of Sleep Medicine [27]. This therapy promotes a reduction of insomnia symptoms and can relieve or reduce pain in children and adults with persistent pain [28].

\section{Conclusions}

Based on the literature cited, we recommend the implementation of professional guidance for children and parents of children with JIA that will improve sleep hygiene and treat sleep problems. These sleep issues are of major importance to caregivers, as well as care providers. We highlight the integrative analysis of the health implications of JIA, regarding both the patient and their caregiver. In this context, the role of experts in integrative and sleep medicine are essential in the guidance and treatment of these families. For this reason, sleep issues should be evaluated for by all care providers of children with JIA and other chronic illnesses and studied more in research. We believe that we may be able to decrease the incidence and severity of these sleep problems and consequently reduce chronic pain in these patients.

\section{Competing interests}

The authors declare that they have no competing interests.

\section{Acknowledgments}

I, Karen Nozoe, certify that all people who have made substantial contributions to this manuscript were considered co-authors (e.g., conception, data analysis, drafting of the critical revision for important intellectual content, writing, editing assistance and final approval of the version to be published). Also, the authors declare that they have no conflicts of interest.

\section{Funding sources}

The authors wish to acknowledge the Associação Fundo de Incentivo à Pesquisa (AFIP), the Conselho Nacional de Desenvolvimento Científico e Tecnológico (CNPq) of Brazil and São Paulo Research Foundation (FAPESP) (grant \#2012/08587-8 to K.T.N.) for financial support. ST and MLA are recipients of fellowships from CNPq.

Received: 30 January 2014 Accepted: 20 May 2014

Published: 3 June 2014

\section{References}

1. Mawani N, Amine B, Rostom S, El Badri D, Ezzahri M, Moussa F, Shyen S, Gueddari S, Wabi M, Shkirat B, Hassouni NH: Moroccan parents caring for children with juvenile idiopathic arthritis: positive and negative aspects of their experiences. Pediatr Rheumatol Online J 2013, 11:39

2. Sacks JJ, Helmick CG, Luo YH, llowite NT, Bowyer S: Prevalence of and annual ambulatory health care visits for pediatric arthritis and other rheumatologic conditions in the United States in 2001-2004. Arthritis Rheum 2007, 57:1439-1445

3. Glass DN, Giannini EH: Juvenile rheumatoid arthritis as a complex genetic trait. Arthritis Rheum 1999, 42:2261-2268. 
4. Thastum M, Herlin T, Zachariae R: Relationship of pain-coping strategies and pain-specific beliefs to pain experience in children with juvenile idiopathic arthritis. Arthrit Care Res 2005, 53:178-184

5. Porkka-Heiskanen T, Zitting KM, Wigren HK: Sleep, its regulation and possible mechanisms of sleep disturbances. Acta Physiol 2013, 208:311-328.

6. Bloom BJ, Owens JA, McGuinn M, Nobile C, Schaeffer L, Alario AJ: Sleep and its relationship to pain, dysfunction, and disease activity in juvenile rheumatoid arthritis. J Rheumatol 2002, 29:169-173.

7. Ward TM, Ringold S, Metz J, Archbold K, Lentz M, Wallace CA, Landis CA: Sleep disturbances and neurobehavioral functioning in children with and without juvenile idiopathic arthritis. Arthritis Care Res (Hoboken) 2011, 63:1006-1101.

8. Twilt M, Schulten AJ, Nicolaas P, Dülger A, van Suijlekom-Smit LW: Facioskeletal changes in children with juvenile idiopathic arthritis. Ann Rheum Dis 2006, 65:823-825.

9. Ward TM, Rankin S, Lee KA: Caring for children with sleep problems. J Pediatr Nurs 2007, 22:283-296.

10. Miles MS, Holditch-Davis D: Enhancing nursing research with children and families using a developmental science perspective. Annu Rev Nurs Res 2003, 2:1-20.

11. Bromberg MH, Gil KM, Schanberg LE: Daily sleep quality and mood as predictors of pain in children with juvenile polyarticular arthritis. Health Psychol 2011, 31:202-209.

12. Shapiro C, Girdwood P: Protein synthesis in rat brain during sleep. Neuropharmacology 1981, 20:457-460.

13. Fadda P, Tortorella A, Fratta W: Sleep deprivation decreases mu and delta opioid receptor binding in the rat limbic system. Neurosci Lett 1991, 129:315-317.

14. Neufeld KM, Karunanayake CP, Maenz LY, Rosenberg AM: Stressful life events antedating chronic childhood arthritis. J Rheumatol 2013, 40:1756-1765

15. Irwin MR, Wang M, Campomayor CO, Collado-Hidalgo A, Cole S: Sleep deprivation and activation of morning levels of cellular and genomic markers of inflammation. Arch Intern Med 2006, 166:1756-1762.

16. Palma BD, Gabriel A Jr, Colugnati FA, Tufik S: Effects of sleep deprivation on the development of autoimmune disease in an experimental model of systemic lupus erythematosus. Am J Physiol Regul Integr Comp Physiol 2006, 291:R1527-R1532.

17. American Academy of Sleep Medicine: International Classification of Sleep Disorders, 2nd ed.: Diagnostic and Coding Manual. Westchester, Illinois: American Academy of Sleep Medicine; 2005.

18. Komada Y, Adachi N, Matsuura N, Mizuno K, Hirose K, Aritomi R, Shirakawa S: Irregular sleep habits of parents are associated with increased sleep problems and daytime sleepiness of children. Tohoku J Exp Med 2009, 219:85-89.

19. Lustig JL, Ireys HT, Sills EM, Walsh BB: Mental health of mothers of children with juvenile rheumatoid arthritis: appraisal as a mediator. J Pediatr Psychol 1996, 21:719-733.

20. Reisine ST: Arthritis and the family. Arthritis Care Res 1995, 8:265-271.

21. Shulz R, Sherwood PR: Physical and mental health effects of family caregiving. Am J Nurs 2008, 108:23-27.

22. Pawl JD, Lee S-Y, Clark PC, Sherwood PR: Sleep characteristics of family caregivers of individuals with a primary malignant brain tumor. Oncol Nurs Forum 2013, 40:171-179.

23. Ruiz FS, Andersen ML, Martins RC, Zager A, Lopes JD, Tufik S: Immune alterations after selective rapid eye movement or total sleep deprivation in healthy male volunteers. Innate Immun 2012, 1:44-54.

24. Mullington JM, Haack M, Toth M, Serrador JM, Meier-Ewert HK: Cardiovascular, inflammatory, and metabolic consequences of sleep deprivation. Prog Cardiovasc Dis 2009, 51:294-302.

25. Banks S, Dinges DF: Behavioral and physiological consequences of sleep restriction. J Clin Sleep Med 2007, 5:519-528.

26. Mausbach BT, Chattillion EA, Roepke SK, Patterson TL, Grant I: A comparison of psychosocial outcomes in elderly Alzheimer caregivers and noncaregivers. Am J Geriatr Psychiatry 2013, 1:5-13.
27. Perlis ML, Jungquist C, Smith MT, Posner D: Cognitive Behavioral Treatment of Insomnia: A session-by-session guide. New York, NY: Springer; 2005.

28. Vitiello MV, Rybarczyk B, Von Korff M, Stepanski EJ: Cognitive behavioral therapy for insomnia improves sleep and decreases pain in older adults with co-morbid insomnia and osteoarthritis. J Clin Sleep Med 2009, 5:355-362.

doi:10.1186/1546-0096-12-20

Cite this article as: Nozoe et al:: The role of sleep in Juvenile idiopathic arthritis patients and their caregivers. Pediatric Rheumatology 2014 12:20.

\section{Submit your next manuscript to BioMed Central and take full advantage of:}

- Convenient online submission

- Thorough peer review

- No space constraints or color figure charges

- Immediate publication on acceptance

- Inclusion in PubMed, CAS, Scopus and Google Scholar

- Research which is freely available for redistribution

Submit your manuscript at www.biomedcentral.com/submit
C Biomed Central 